\title{
MANAGEMENT OF ENVIRONMENTAL ETHICS APPROACH TO STUDENTS
}

\author{
Dony Andrasmoro \\ Lecturer in Geography Education Study Program, Faculty of IPPS, IKIP PGRI Pontianak, \\ Jalan. Ampera, No. 88 Pontianak \\ donny.andrasmara@gmail.com
}

\begin{abstract}
The purpose of this study was to determine the role of students in the level of awareness of environmental phenomena at the IKIP PGRI Pontianak Campus. the aim of building student awareness about the environment through Population and Environmental Education (PKLH) courses to support sustainable development. this research method is descriptive qualitative with the knowledge triangle learning approach based on interactive discussion analysis of knowledge, education and environmental innovation. the results of research by utilizing interactive discussion methods can encourage changes in students' attitudes to be orderly and respect environmental aspects by strengthening environmental ethics. The results of the learning analysis study were conducted using an out class teaching system. managing the results of the implementation of case studies and the reality of the results of theoretical studies that are implemented against the phenomenon of potential environmental problems. out class implementation building eduction of disaster mitigation management to environmental problems that focus on the phenomenon of inorganic waste. the role of the results of the study of strengthening environmental ethics in supporting student awareness with management efforts oriented towards economic, social and environmental approaches based on sustainable development.
\end{abstract}

Keywords: Ethics, Environment, Students.

\section{PRELIMINARY}

Environmental damage in West Kalimantan is mostly caused by conditions and phenomena of large-scale land use change so that the impact is greater. lately there has been environmental damage caused by the conversion of forest land into plantations due to land burning resulting in air pollution, namely haze. besides that the problem of waste has become one of the phenomena of environmental effort that has yet to be resolved. Indonesia is recorded as the second largest contributor of waste after China, which is around 64 million tons / year (BPS, 2019).

Increasing environmental problems in Indonesia are an indicator of the destruction of forest ecosystems. Considering the vegetation factor in Indonesia is in the equatorial zone with very 
high rainfall intensity. One of these aspects makes Indonesia dominated by tropical forests. (Andrasmoro, 36: 2017).

The environment is a unity of space with all objects, power, and conditions of living things, including humans and their behavior that affects the survival and welfare of humans and other living things. humans can enjoy all the contents of nature in their environment. Existing in the utilization and at the same time maintain it in order to remain sustainable. Humans have advantages because they are equipped with thoughts (Hanny Mulyawati et al., 2015). topographic conditions in general, the land of West Kalimantan is a lowland and has hundreds of rivers that are safe to navigate, a bit hilly that stretches from West to East along the Kapuas Valley and the Natuna Sea / Karimata Strait. some of this land area swamps mixed with peat and mangrove forests. (Provincial Government of West Kalimantan, 2019). Therefore, the river becomes an alternative source of life and also becomes an environmental problem, which is of course the problem of waste.

Education is the activity of a person or group of people to achieve educational goals. Assistance activities in education can be in the form of education management and can also be in the form of activities such as guidance, teaching and or training. based on Law No 20 of 2003 concerning national education (SISDIKNAS) article 3 states that:

"National education serves to develop capabilities and shape the dignified character and civilization of the nation in the context of developing the intellectual life of the nation which aims to develop the potential of students to become people of faith and to fear God Almightynoble, healthy, competent, creative, knowledgeable, independent and become a democratic and responsible citizen"

Etymology ethics comes from Greek, which is ethos which means character to custom or custom. .ethics is usually closely related to moral words which is a Latin term, namely mos and in the form of plural mores, which also means customs or ways of life of someone by doing good deeds (decency) and avoiding things that are bad actions. the philosopher Aristotle in his book Ethics Nikomacheia explains the discussion of ethics as follows:

\section{Terminius Techicus}

Understanding ethics in this case, ethics is studied for science that studies the problem of human actions or actions.

\section{Manner and Custom}

Discuss ethics relating to the procedures and habits (customs) inherent in human nature (Inherent in human nature) which are bound by the notion of "good and bad" a human 
behavior or deeds (Rosady Ruslan, 2004)environmental awareness began to be born in 1950 when pollution began to emerge from agricultural factories and transportation factories in developed countries. as pollution problems go hand in hand with the rapid growth of industry in developed countries such as America, Europe and Japan, book 4 by Rachel Carson is nicknamed The Silent Spring, which illustrates how threatened humans and living creatures and nature have been peaceful, but withthe presence of the industry becomes damaged and polluted.this book then raises awareness of doing something from the threat of the environment (Hanny Mulyawati et al., 2015) .

\section{METHOD}

The method used is descriptive qualitative. Qualitative analysis is a method that describes qualitatively facts, data, objects, material in the form of language expressions or discourse through appropriate and systematic interpretation (Wibowo, 2014). data on environmental problems integrated with the PKLH course approach in managing sustainable development by encouraging the strengthening of the knowledge triangle learning system based on interactive discussion of knowledge, education and environmental innovation analysiscollaborated in a descriptive qualitative analysis by interpreting facts found in the field.

The data collected consists of primary data and secondary data. Primary data obtained directly through field studies, namely class analysis studies, while secondary data through literature studies, literature from existing data sources or information. Data was collected using combined data collection techniques in the form of interviews and direct documentation with or discussion approaches, study documentation and literature as well as direct observation on site. Data analysis was performed descriptively qualitatively by tabulating data obtained in accordance with the objectives.

\section{RESULT AND DISCUSSION}

\section{a. Research Sites}

The research was carried out in Class B Morning Semester 5 Geography Education Study Program Faculty of Education and Social Sciences (F.IPPS) IKIP PGRI Pontianak. 


\section{b. Environmental Based Research Findings}

1) Implementation of the knowledge triangle learning system

The role and management of PKLH learning in the Geography education Study Program become a very important aspect in which the orientation of the management of learning and lectures takes precedence over the environment and sustainable development approach. indirectly the role and research results of lecturers and students become a parameter in building the carrying capacity of environmental awareness that is integrated with the community, through students with approaches in lectures carried out with cooperative learning methodology and study analysiscase. the out class based learning process becomes a priority to priority to build a culture of respecting the environment with the triangle knowledge approach :

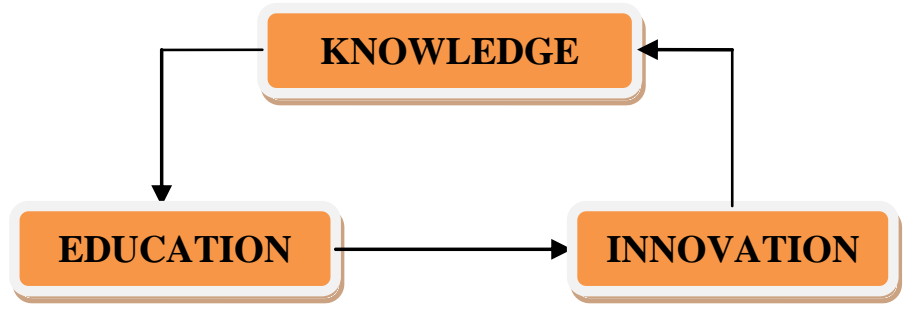

Figure1. Tri Angel of knowledge

a) Knowledge

the concept of the awareness approach and planting of environmental ethics in class B. In the 5th Semester 5 the Geography Education Study Program was implemented through strengthening the Geography Education Study Program Vision and Vision approach since 2015 namely "Creating a superior Geography education study program andhaving an environmental perspective and forming competent and innovative geography teachers in Geography learning in 2019 ". implementation of strengthening connected knowledge in all activities both in academic programs, Community Service Program (PKM), Geography Student Association Work Program (HIMAGEO) and collaboration management. from the results of observational studies that the strengthening of environmental ethics has been running since the first semester students. The pattern of daily activities of students gives the impact of changing attitudes in the management of sustainable environmental maturity. However all aspects of knowledge management are not all students can apply but the progress of change is changing the conditions and habits 
of the study program environment. the social approach becomes a guide for students that performance orientation geography and scientific studies must contain elements of the environmental approach

b) Education

Strengthening education and teaching is done by a variety of sources and types of courses. Population and Environmental Education (PKLH) one of the elements of the MPB (Behavioral Behavior) course in the KKNI curriculum component recommends that the MPB course family is a pattern of strengthening attitudinal changes in the code of ethics for environment and sustainable development. learning in the approach leads to the realm of interactive contextual approaches, discussions and case studies. Case study based learning is oriented to environmental problems and environmental issues in West Kalimantan Province. comprehensively the theme of the approach is the issue of pollution from various aspects caused by inorganic waste. out class learning management provides more varied learning methods and strategies so that the aspect of PKLH learning achievement is more directed and builds strengthening of changes in attitudes, student behavior in protecting the surrounding environment. This aspect is in accordance with PKLH Course Learning Achievement, namely that Students are able to understand the nature, concepts, scope, methods and objectives of PKLH, develop insights and attitudes as well as analysis in solving population problems, the environment and have skills in implementing PKLH in school and outside of school.

c) Innovation

Learning management efforts must generate ideas and innovations about solutions to environmental problems. The theme of inorganic waste management cannot be resolved significantly. through the results of studies and study data from the assignments of PKLH subject students that the average community does not yet understand the orderliness of waste problems. orientation of the learning process based on environmental ethics is also carried out using a map media with a spatial approach, so that the problem analysis will be managed and developed based on the use of map analysis studies. the use of maps in this case is done by lecturers is the Rupa Bumi Map (RBI) and the Thematic Map in accordance with the theme of 
environmental problems. Out class-based innovation learning process also provides innovation encouragement inorganic waste theme management. Case studies in the IKIP PGRI Pontianak campus environment still need to be improved in terms of environmental friendly waste management technology. Namely students make a draft report on the ways, theories and mechanisms of empowering plastic waste into aspects of economic value. students are required to make innovation proposals and be submitted in various environment-based innovation competitions. This indicator is one of the assessment points in building an orderly culture of the surrounding environment. Information Technology approach in managing PKLH courses is making disaster prone maps or maps of potential disasters due to environmental damage in West Kalimantan Province. the carrying capacity of the management of innovative learning based on the environment also has an impact on environmental change, especially in the attitude culture to the people of West Kalimantan so that it supports the achievement of a Trash Free Indonesia in 2020.increasingly integrated in supporting the vision of Pontianak City 2018-2023 namely "Pontianak City Equatorial, Environmentally Friendly, Smart and Dignified". environmentally friendly means that in developing its territory, the Pontianak City Government must create a clean, healthy, green and beautiful environment by prioritizing local wisdom.

2) Approach to the Components of Environmental

Ethics environmental management and development is increasingly rapid with increasingly worrisome conditions and situations, in this case having an impact on the patterns and behaviors of IKIP PGRI Pontianak students, namely the conditions and situations depend on the patterns and behavior that will be confronted directlywith friendly hospitality of the environment.standpoint of approach based on the role and contribution of environmental ethics. The results of the management of interaction between humans and nature produce a culture and experience of their own, so that it becomes a local wisdom. Therefore, in applying environmental ethics must pay attention to the following four things that will be collaborated with the management of the implementation of the results of the study process of PKLH courses in the geography education program of IKIP PGRI Pontianak according to (Atok Miftachul Hudha et al, 2019), States that : 
1. Humans as part of the environment are the main actors in environmental management, so they need to love all life and environment other than themselves. in the learning process of PKLH in approach to the concept of planting attitudes to encourage behavior patterns that are friendly to the conditions and environmental situations will have an impact on the community and other colleagues to create a good environment and encourage changes in attitudesmore innovative in dealing with environmental phenomenon problems.

2. Humans as part of the environment are the main actors in environmental management, so they must always strive to preserve nature, balance and beauty. the learning process in the PKLH course in the class encourages the situation to be orderly about the use of plastic waste, striving to minimize plastic waste and utilizing it with an innovative and environmentally friendly approach that is a lifestyle concept that can solve problems is stylelife that holds the principle of sustainability and applies environmental ethics in its life and applies the 4R principle, namely: Reduce (reduce the use of natural resources), Reuse (reuse resources that can still be used), Recycle (recycle materials), and replanting(replanting).

3. Policies on the use of limited natural resources, for example energy. The PKLH course recommends the strategic message of limiting the use of appropriate natural resources and developing disciplined lifestyle in all aspects.

4. The environment is provided for all living things, not just humans.developing the concept of environmental ethics that strengthens awareness of students of the importance of the environment for the common good, the concept of this approach is carried out in encouraging innovative values of students with the participatory role of daily life. the implementation of the concept of learning management is carried out in the evaluation of learning by giving assignments as a responsibility for environmental wisdom in order to remain sustainable. teaching evaluation on integrated PKLH by making sub-themes of solving simple environmental problems namely: the utilization of sufficient water, protecting the preservation of plants, building social life in dealing with environmental problems to create student work programs insupport environmental activities.such as work programs commemorating environmental days, world water days, earth days and other 
environmental activities that build change without coercion. students are encouraged to collaborate with government, NGOs and the community to care about the environment in order to encourage management and build environmental awareness together.

\section{c. Important role of environmental ethics towards sustainable development for IKIP PGRI Geography education students in Pontianak.}

Encouraging the carrying capacity of sustainable development for students for the benefit of the environment becomes a benchmark in the success of PKLH courses. management and the core of the achievement is the pattern and collaboration of social, economic and environmental aspects (ecology) itself. this aspect is one of the goals of PKLH success which is sought to be oriented towards the community and the next generation which can also be implemented to students in schools. the development of the concept of sustainable development needs to consider socially and culturally reasonable needs, students are required to be able to disseminate values that create different consumption standards within the limits of environmental capabilities, as well as for all capable peopledream of it.however there is a tendency that the fulfillment of these needs will depend on the needs in realizing economic growth or production needs at the maximum scale that occurs in the community.

Sustainable development clearly requires economic growth in a place where its main needs cannot be consistent with economic growth, provided the contents of growth reflect the principles of sustainability. however, the reality is that high production activities can occur together with community poverty. This condition can endanger the environment. so that the community's sustainable development is met by need by increasing their production potential and at the same time guaranteeing equal opportunities for all people. This orientation must be embedded in geography education students of IKIP PGRI Pontianak.

Strengthening sustainable development in an environmental approach that is expected to later graduate students is the concept of what is implemented by students in supporting environmentally friendly development will have an impact on future development so that it contributes to studentsit consists in creating economic well-being.Even though the mechanism and operational implementation of the environmental awareness independence approach is not easy, the concept of change by students must continue to 
move towards the achievement of strengthening control and disaster risk reduction. in this case Indonesia is very prominent in the impact of plastic waste.the pattern of discipline in a community, especially in the province of West Kalimantan must be maintained not only from lecturers, students but all elements of society together with the government and other environmentally friendly alliances.

\section{CONCLUSION}

Building and protecting the environment is a priority for all parties, in this case the Population and Environmental Education Course (PKLH) encourages attitude change through the concept of environmental ethics development with a sustainable development approach that must continue to be developed. through a learning approach to prospective teacher students, it becomes an opportunity in management that will later be brought to school as a discourse to reduce the risk of disaster even worse. Waste management approach becomes the initial alternative of one of the waste problems in West Kalimantan Province so that management is sought with an innovative, creative and responsive value approach by synergizing the carrying capacity of the knowledge triangle concept as the carrying capacity of reinforcementincreasing knowledge based on data and facts.character education by prioritizing changes in attitudes and behaviors that are environmentally sound and innovative in developing a more enjoyable learning process, producing agents of change in sustainable development in all aspects of community life in a balanced and balanced mannersustainability in West Kalimantan Province.

\section{REFERENCE}

Anonymous.2008. National Education System. "in https ://fadloly master teacher.wordpress.com. Accessed October 15, 2019.

Atok Miftachul Hudha, Husamah, Abdulkadir Rahardjanto. 2019. Environmental Ethics (Theory and Practice of Learning). Malang: Publisher of State University of Malang.

Dony Andrasmoro, Endah Evy Nurekawati. 2017. Analysis of the Development of Smallholder Forest Policy (HTR) Towards Improvement of Community Welfare in West Kalimantan and D.I Yogyakarta. Swarnabhumi Journal ISSN 2548-5563, Vol. 2 Number. 1, Journal of Geography and Geography Learning, Study Program of Geography at PGRI University in Palembang.

Mulyawati, Hanny et al., (2015). Social Studies Learning. Bandung: Alfabeta. 
Provincial Government of Kalbar.2019. "An Overview of the Geographical Aspects of West Kalimantan" in http://www.kalbarprov.go.id (accessed 10 November 2019).

Ruslan, Rosady. (2004). Public Relations Ethics Conception \& Application. North Jakarta: PT. RajaGrafindo Persada.

Subakti Arwin, 2015. "Population and Environmental Education". jakarta, Graha Ilmu.

Wibowo, W. 2014. "The Smart Way to Write Scientific Articles". Compass. Jakarta: http://www.puslitsosekhut.web.id. 